Gut, 1978, 19, 336-338

\title{
Induction of gastro-oesophageal reflux by alcohol
}

\author{
S. E. KAUFMAN AND M. D. KAYE \\ From the University of Vermont-College of Medicine, Burlington, Vermont 05401, USA
}

SUMMARY In order to establish whether alcohol in amounts customarily imbibed during social drinking causes gastro-oesophageal reflux, 12 healthy young individuals, without symptoms of gastro-oesophageal reflux, were studied twice. Each time, distal oesophageal $\mathrm{pH}$ was monitored continuously for three hours after a standard meal which included either $180 \mathrm{ml} 100$ proof vodka or $180 \mathrm{ml}$ water. The order of studies with and without alcohol was random. Peak blood alcohol concentrations ranged between 0.63 and $1.29 \mathrm{~g} / \mathrm{l}$. Eleven of the 12 subjects refluxed more after alcohol; and the difference in mean reflux scores for studies with and without alcohol was highly significant. We conclude that relatively modest quantities of alcohol induce gastro-oesophageal reflux in healthy people.

Individuals prone to gastro-oesophageal reflux frequently state that heartburn, the cardinal symptom of reflux, is especially likely to occur after drinking alcohol; and there is a widespread clinical impression that the incidence of peptic oesophagitis is increased in chronic alcoholics, in whom disordered oesophageal motility may occur (Winship et al., 1968). Moreover, a decrease in lower oesophageal sphincter pressure (LOSP) has been noted after acute ethanol ingestion in normal subjects (Hogan et al., 1972). However, the correlation between lower oesophageal sphincteric pressure and the likelihood of gastro-oesophageal reflux is imperfect (Ismail-Beigi et al., 1970; Haddad, 1970; Bennett, 1973) and LOSP is an indirect and somewhat unsatisfactory indicator of sphincteric incompetence.

This study was designed to investigate the competence of the lower oesophageal sphincter, as assessed directly by intraoesophageal $\mathrm{pH}$ recording, after alcohol ingestion in normal subjects. This method for assessment of gastro-oesophageal reflux has been described in a previous report (Kaye, 1977) in which the frequency of post-prandial reflux in healthy asymptomatic individuals was documented.

\section{Methods}

SUBJECTS

Twelve healthy, freely consenting, fully informed volunteers, aged between 20 and 27 (mean 24.8)

Received for publication 8 November 1977 years were studied. Nine were men and three women. None had symptoms of gastro-oesophageal reflux (heartburn, regurgitation of sour or bitter-testing fluid); had a history of upper gastrointestinal disorders; took antacids; had undergone radiological examination for upper gastrointestinal symptoms; or had had upper abdominal surgery.

\section{MANOMETRY}

Oesophageal manometry was performed to determine the exact location of the lower oesophageal sphincter, so that a pH electrode could be appropriately positioned in subsequent studies (see below). After an overnight fast, a triple-lumen tube complex (overall diameter approximately $3 \mathrm{~mm}$ ) with lateral recording openings $5 \mathrm{~cm}$ apart, was passed through the mouth into the stomach. Each lumen was continuously perfused at a rate of 0.5 to $1 \mathrm{ml}$ per minute with water by means of a pneumohydraulic capillary infusion system (Arndorfer Medical Specialties Co., Greenfield, Wisconsin, USA), and was connected to an external transducer (Bell \& Howell, 4-327-I), the output of which was recorded on a Gilson Multi-Channel Recorder with a paper speed of $2.5 \mathrm{~mm} / \mathrm{s}$. Swallowing was monitored by electromyograph, and respiration by a flexible bellows placed aroung the lower chest and connected to the recorder through a separate transducer. Lower oesophageal sphincteric pressures were measured during $0.5 \mathrm{~cm}$ step-wise withdrawals of the catheter from the stomach into the oesophagus. Responses of the oesophageal body to voluntary swallowing were then recorded, and were found to be normal in all subjects. 
DISTAL OESOPHAGEAL PH RECORDING

Each subject underwent two studies, before each of which alcohol was proscribed for 48 hours. After an overnight fast, a small pH electrode (Radiometer GK 282C, Copenhagen, Denmark) was passed through the mouth, positioned $3 \mathrm{~cm}$ above the upper margin of the lower oesophageal sphincter, and fixed in place by taping to the cheek. The electrode was connected to a $\mathrm{pH}$ meter (Radiometer PHM 62), the output of which was recorded on a Gilson Multi-Channel Recorder. The subject then ate a standard meal, which consisted of two scrambled eggs, two slices of buttered toast, and one cup of coffee. By random allocation on alternate days, each subject slowly sipped during the meal either $180 \mathrm{ml} 100$ proof vodka, or $180 \mathrm{ml}$ water, each in $180 \mathrm{ml}$ orange juice. Thirty minutes after the beginning of the meal, the subject was positioned supine on a bed with one pillow, and oesophageal $\mathrm{pH}$ was then recorded continuously for three hours. A flexible bellows was placed around the chest for recording of respiration. Subjective reports of belching, heartburn, or singultus were marked on the tracing, and periods of sleep or intoxication were also noted. As the only variable that differed for the two studies was alcohol, each subject acted as his own control.

\section{COLLECTION OF BLOOD SAMPLES}

During the oesophageal pH study with alcohol, serial samples of $5 \mathrm{ml}$ were obtained through a heparin lock 30, 60, 90, 120 and 180 minutes after the beginning of $\mathrm{pH}$ recording. After heparinisation and centrifugation, serum samples were stored at $-20^{\circ} \mathrm{C}$, and blood ethanol levels were subsequently determined by the ethanol dehydrogenase method of Stiles et al. (1966).

\section{ANALYSIS OF RECORDS}

Reflux was defined as a fall in pH to less than 5; and an episode of reflux as a fall of more than $1 \mathrm{pH}$ unit in less than 20 seconds. Periods of time during which oesophageal $\mathrm{pH}$ was between 5 and 4, 4 and 3, 3 and 2 , and 2 and 1 were measured for each hour of recording, and for the total period of recording. A crude scoring system was devised in order to approximate the amount of reflux in each subject. For $\mathrm{pH}$ periods between 5 and 4, 4 and 3, 3 and 2, and 2 and 1 , multiplication factors of $1,2,3$, and 4 , respectively, were applied.

The significance of differences was calculated by the Wilcoxon signed-ranks test.

\section{Results}

Maximum resting end-expiratory pressures in the
LOS ranged between 1.33 and $3.19 \mathrm{k} \mathrm{Pa}$ (mean $2 \cdot 13 \mathrm{k} \mathrm{Pa}$ ).

All 12 subjects completed the study uneventfully, though each exhibited mild to moderate intoxication, as reflected by somnolence and/or alterations in mood or speech. No one vomited or complained of nausea. Two subjects experienced heartburn after alcohol, but none noted this symptom during the study without alcohol. Peak blood ethanol levels in excess of $1 \mathrm{~g} / \mathrm{l}$ occurred in seven of 12 subjects, and the mean peak concentration, 60 minutes after ingestion of the meal, was $0.987 \pm 0.237 \mathrm{~g} / \mathrm{l}$ (mean \pm SD). Mean blood alcohol levels are shown in the Figure.

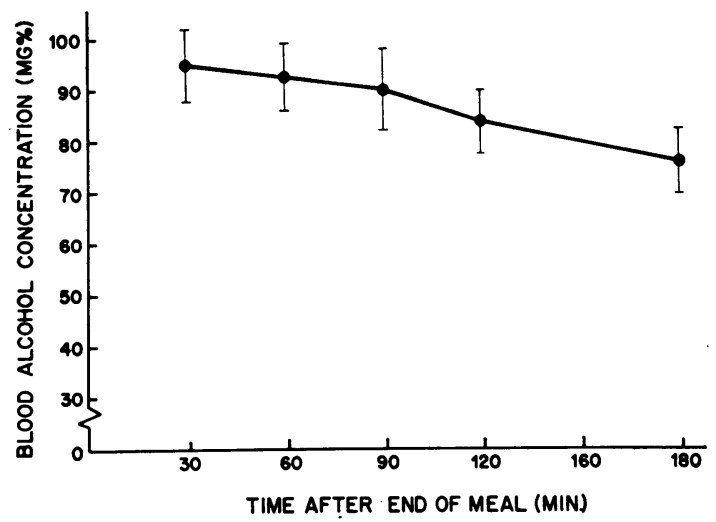

Figure Blood alcohol concentrations after the meal with alcohol. Each point represents mean $\pm 1 S E$ for the 12 subjects.

In accordance with previous observations (Kaye, 1977), each of the 12 subjects had episodes of gastrooesophageal reflux after the meal without alcohol. One of the 12, who had a very low total reflux score (13.5) without alcohol, did not reflux at all after alcohol. In each of the remaining 11 subjects, reflux scores with alcohol were higher than those without. The differences between studies with and without alcohol, for a number of reflux parameters-number of reflux episodes, total reflux scores, and reflux scores during the first hour, the second hour, and the third hour-were statistically significant (Table).

\section{Discussion}

Reflux oesophagitis is a relatively common gastrointestinal problem which may be associated with substantial morbidity. Although the relative importance of different factors in its pathogenesis have not been fully elucidated, it is well established that initiation of the problem requires gastro-oesophageal 
Table Gastro-oesophageal reflux with and without alcohol*

\begin{tabular}{|c|c|c|c|c|c|c|c|c|c|c|}
\hline \multirow[t]{2}{*}{ Subject } & \multirow{2}{*}{\multicolumn{2}{|c|}{$\begin{array}{l}\text { Reflux } \\
\text { episodes (no.) }\end{array}$}} & \multicolumn{8}{|c|}{ Reflux scores } \\
\hline & & & \multicolumn{2}{|c|}{3 hours total } & \multicolumn{2}{|l|}{ Hour 1} & \multicolumn{2}{|l|}{ Hour 2} & \multicolumn{2}{|l|}{ Hour 3} \\
\hline $\begin{array}{r}1 \\
2 \\
3 \\
4 \\
5 \\
6 \\
7 \\
8 \\
9 \\
10 \\
11 \\
12\end{array}$ & $\begin{array}{r}8 \\
5 \\
8 \\
8 \\
11 \\
42 \\
8 \\
4 \\
11 \\
8 \\
0 \\
14\end{array}$ & $\begin{array}{r}4 \\
3 \\
9 \\
3 \\
3 \\
34 \\
4 \\
5 \\
1 \\
5 \\
1 \\
5\end{array}$ & $\begin{array}{r}81 \cdot 8 \\
143 \cdot 8 \\
150 \cdot 4 \\
97 \cdot 2 \\
334.5 \\
338 \cdot 3 \\
30.0 \\
58.9 \\
430 \cdot 0 \\
343 \cdot 8 \\
0 \\
306.5\end{array}$ & $\begin{array}{r}10 \cdot 7 \\
28 \cdot 6 \\
90 \cdot 4 \\
10 \cdot 3 \\
52 \cdot 4 \\
209 \cdot 6 \\
10 \cdot 0 \\
8 \cdot 2 \\
9 \cdot 3 \\
38 \cdot 1 \\
13 \cdot 5 \\
66.9\end{array}$ & $\begin{array}{c}9.3 \\
75 \cdot 4 \\
108 \cdot 5 \\
59 \cdot 0 \\
104.4 \\
44.9 \\
16.9 \\
0 \\
118 \cdot 3 \\
279 \cdot 6 \\
0 \\
111 \cdot 7\end{array}$ & $\begin{array}{r}3.5 \\
28.6 \\
32.0 \\
1.0 \\
35.5 \\
82.4 \\
10.0 \\
2.0 \\
9.8 \\
37.7 \\
13.5 \\
61.4\end{array}$ & $\begin{array}{r}28 \cdot 0 \\
68 \cdot 5 \\
14 \cdot 3 \\
38 \cdot 2 \\
124 \cdot 2 \\
144 \cdot 0 \\
13 \cdot 2 \\
58 \cdot 9 \\
174 \cdot 5 \\
64 \cdot 2 \\
0 \\
136 \cdot 1\end{array}$ & $\begin{array}{l}7 \cdot 2 \\
0 \\
47 \cdot 3 \\
9 \cdot 3 \\
17 \cdot 0 \\
93 \cdot 4 \\
0 \\
4 \cdot 0 \\
0 \\
0 \cdot 3 \\
0 \\
0 \cdot 2\end{array}$ & $\begin{array}{c}44 \cdot 5 \\
0 \\
27 \cdot 7 \\
0 \\
105 \cdot 9 \\
149 \cdot 3 \\
0 \\
0 \\
137 \cdot 2 \\
0 \\
0 \\
58 \cdot 7\end{array}$ & $\begin{array}{l}0 \\
0 \\
11 \cdot 1 \\
0 \\
0 \\
33 \cdot 8 \\
0 \\
2 \cdot 2 \\
0 \\
0 \\
0 \\
5 \cdot 4\end{array}$ \\
\hline $\mathbf{P}+$ & \multicolumn{2}{|c|}{0.0034} & \multicolumn{2}{|c|}{0.0005} & \multicolumn{2}{|c|}{0.0105} & \multicolumn{2}{|c|}{0.0034} & \multicolumn{2}{|c|}{0.0156} \\
\hline
\end{tabular}

"Definitions of "Reflux Episode" and "Reflux Score" are in the text.

†Significance of differences between studies with and without alcohol. Wilcoxon signed-ranks test, one tailed.

reflux secondary to incompetence of the lower oesophageal sphincter. In earlier studies (Hogan et al., 1972), normal subjects were found to have impairment of oesophageal propulsive motor activity and reduction of lower oesophageal sphincter pressure after $350 \mathrm{ml}$ of whisky (bourbon). These observations provided indirect evidence that alcohol might adversely affect competence of the lower oesophageal sphincter. Our studies provide direct evidence for such an adverse effect; and it should be emphasised that the amount of alcohol which we gave-namely, $180 \mathrm{ml}$ vodka-is within the range of that taken frequently by many members of the adult population.

The design of this study does not allow us to pinpoint directly the mechanism by which alcohol induces reflux of gastric contents into the oesophagus. Theoretically, this effect could be secondary not only to weakening of the lower oesophageal sphincter, but also to stimulation of gastric acid secretion, or to impairment of gastric emptying, a possibility which is to some extent supported by the observations of Cooke (1972), and Harichaux et al. (1970). However, in view of the manometric studies of Hogan et al. (1972), it seems probable that induction of reflux by alcohol is due, at least in part, to its adverse affect upon the lower oesophageal sphincter. Whatever the mechanism, our results suggest that alcohol may contribute to the development of reflux oesophagitis in some individuals; and they provide a solid foundation for proscription of alcohol in patients with symptomatic gastrooesophageal reflux or established oesophagitis.
This investigation was supported by a research grant from the Distilled Spirits Council of the United States, Inc., and by Grant RR109 from the General Research Centers Program of the Division of Research Resources, National Institutes of Health, Bethesda, Maryland, U.S.A. We are grateful to Michael Costanza, $\mathrm{PhD}$, for help with the statistical analysis.

\section{References}

Bennett, J. R. (1973). Symposium on gastro-oesophageal reflux and its complications. Section 5: The physician's problem. Gut, 14, 246-249.

Cooke, A. R. (1972). Ethanol and gastric function (Letter). Gastroenterology, 62, 501-502.

Haddad, J. K. (1970). Relation of gastrooesophageal reflux to yield sphincter pressures. Gastroenterology, 58, 175-184.

Harichaux, P., Capron, J. P., Lienard, J., Freville, M. (1970). Influence de l'éthanol sur l'évacuation gastrique. Etude clinique et expérimentale, Lille Med, 15, 1059-1065.

Hogan, W. J., Viegas de Andrade, S. R., Winship, D. H. (1972). Ethanol-induced acute esophageal motor dysfunction. Journal of Applied Physiology, 32, 755-760.

Ismail-Beigi, F., Horton, P. F., Pope, C. E., II (1970). Histological consequences of gastrooesophageal reflux in man. Gastroenterology, 58, 163-174.

Kaye, M. D. (1977). Postprandial gastro-oesophageal reflux in healthy people. Gut, 18, 709-712.

Stiles, D., Batsakis, J. G., Kremers, B., Brieve, R. O. (1966). The evaluation of ethanol measurements with alcohol dehydrogenase. American Journal of Clinical Pathology, 46, 608-611.

Winship, D. H., Caflisch, C. R., Zboralske, F. F., and Hogan, W. J. (1968). Determination of esophageal peristalsis in patients with alcoholic neuropathy. Gastroenterology, 55, 173-178. 